RESEARCH ARTICLE

\title{
An investigation into barriers to student engagement in Higher Education: Evidence supporting 'the psychosocial and academic trust alienation theory'
}

\author{
Caroline Sarah Jones
}

Education Faculty, Manchester Metropolitan University, Manchester, UK

\section{Check for updates}

Correspondence to: Caroline Sarah Jones, Education Faculty, Manchester Metropolitan University, Birley Campus, Brooks Building, 53 Bonsall Street, Hulme, Manchester M156GX, UK;

E-mail: c.jones@mmu.ac.uk

Received: April 13, 2021;

Accepted: June 7, 2021

Published: June 9, 2021

Citation: Jones CS. An investigation into barriers to student engagement in Higher Education: Evidence supporting 'the psychosocial and academic trust alienation theory'. Adv Educ Res Eval, 2021, 2(2): 153-165. https://doi.org/10.25082/AERE.2021.02.002

Copyright: () 2021 Caroline Sarah Jones. This is an open access article distributed under the terms of the Creative Commons Attribution License, which permits unrestricted use, distribution, and reproduction in any medium, provided the original author and source are credited.

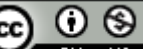

\begin{abstract}
The purpose of this research was to examine the new concept of, "psychosocial and academic trust alienation theory'; the potential influence of self-concept, self-esteem and trust as barriers to student engagement. The study was conducted in a Higher Education University campus located within a 16-19 year old Further Education Institution.A constructivist epistemology, underpinned by symbolic interaction theory utilising a mixed methods approach formed the research design. The sample population were students enrolled at the participating institution and employed teaching staff. Quantitative surveys were completed by 39 students, supported by two qualitative staff focus groups and one qualitative student case study to examine an outlier result. Findings suggest $87 \%$ of the student participant sample aligned with the 'psychosocial and academic trust alienation theory'. Barriers to student engagement were; specific classroom and assessment activities, relationships with teaching staff and peers, staff absences and staff turnover, all having a significant impact on students' psychosocial and academic trust. The contribution of this research to the field of Higher Education is three-fold; firstly, findings support the 'psychosocial and academic trust alienation theory', secondly it provides insights into the psychological barriers to engagement for the Widening Participation student demographic, thirdly it proposes practical strategies for supporting Widening Participation students in Higher Education. Recommendations for practice include i) counselling, coaching and mentoring support from teaching staff, ii) initiatives to reduce staff turnover and sickness, iii) social pedagogical teaching approaches, iv) teacher training, and, v) peer based learning opportunities to cultivate communities of practice. These strategies could strengthen Widening Participation student's psychosocial and academic trust, thus reducing barriers to student engagement in Higher Education, contributing to increased social mobility success rates in the United Kingdom and beyond.
\end{abstract}

Keywords: higher education, widening participation, student engagement, alienation theory

\section{Introduction}

The psychosocial and academic trust theory of student alienation [1] is a new concept, suggesting that self-concept, self-esteem and trust are interconnected, and contribute to barriers to student engagement. This research presents results that support this theoretical perspective in Higher Education (HE) practice.

This original theory was initially observed whilst teaching Widening Participation (WP) students in Higher Education. I began to notice reoccurring patterns of psychological behaviours from students, which seemed to be pivotal for ongoing success or failure. These behaviours were closely associated with the students' self-concept and self-esteem (psychosocial), and appeared to be affecting their ability to trust in the Higher Education Institute (HEI) systems and processes. Thus, I began to develop an interest in investigating HE WP students' psychological needs more closely, in particular, exploring the interplay between these factors and already existing and established theories of alienation [1,2]. I felt compelled to attempt to understand the complex needs of WP HE students [3] to improve teaching practice and long-term outcomes for the WP student demographic. This is important if social mobility in the United Kingdom is to be truly addressed effectively [4] . HEI's also need to demonstrate their commitment to the WP demographic and perhaps with stronger insight, more can be done to secure accomplishment for this complex societal group. WP students have the power to succeed and improved psychological understanding, support and relationship based practice from the HEI could contribute significantly to successful outcomes, such as completion of programmes and levels of achievement on exit. 
Extensive literature on topics such as student engagement, alienation theory [1,2,5-9] and trust [10-14] in HE exist, albeit in isolation. There is an absence of investigation that links the concepts together for the WP HE demographic, notoriously disadvantaged from the outset of University life $[4,15]$. This identified research gap provided the motivation for this research, led by the following research questions:

(1) What are students' perceptions and experiences of barriers to engagement resulting from their own psychosocial self-concept and levels of 'academic trust'?

(2) How do these barriers influence student engagement through alienation?

(3) What are HE staff perceptions and experiences of students' barriers to engagement, based on the relationship between students' psychosocial self-concept and levels of 'academic trust'?

\subsection{Alienation theory}

Alienation can be identified when students present negative attitudes towards their educational experiences and the institution [7,8]. Commonly this can be recognised when students start to reduce attendance, disengage with available resources and support, and stop submitting formative or summative assessments. Çalar's $[7,8]$ ideas of alienation provide a natural pathway to the affirmation that these negative student attitudes create barriers to learning and student engagement. Meanwhile, Case [16] highlights the significance of alienation in relation to students entering the HE domain, feeling a part of the HE community, and ultimately continuing and completing programmes of study. This asserts the importance and value of understanding alienation theories in relation to barriers to student engagement in the HE sector [2].

\subsection{Psychosocial (Self-Concept/Self Esteem)}

Howe [17], explains psychosocial theory as being 'created by the interplay between the individual's psychological condition (student) and the social environment (HEI)'. Schaffer [18] further explains that psychosocial, self-concept has a direct influence on individuals based on their experiences. With regard to a student's involvement in their programme of study, receiving assessment results and feedback can be related to emotions of accomplishment and failure, and subsequent feelings of aptitude or ineffectiveness.

The association between self-concept and self-esteem is explored by Schaffer [18] as 'where there is little discrepancy between the ideal and the perceived real self, the individual will experience high self-esteem; where the discrepancy is great, low self-esteem is the result'. High and low self-esteem in students can manifest in response to many aspects within HE, such as assessment results, feelings of integration within the programme, peer relationships and anxieties from specific types of assessments, for instance presentations.

\subsection{Academic trust}

According to Heffernan, Wilkins and Butt [19], 'students' trust in an educational institution has been shown to have numerous positive outcomes, including confidence to select and enrol in a programme, increased student loyalty and engagement'. However, Kharouf, Sekhon and Roy [20] identify that ownership of trust ultimately belongs to the student and can be affected by the behaviours of the HEI. This suggests that levels of academic trust can change or differ in response to various points of the student's HE experience and in reaction to their own individual psychosocial status. With this in mind, it is in the best interests of both the student and the HEI to foster trusting relationships and begin to understand the psychological needs of their student market. This is particularly pertinent for students who come from a WP background, and have been potentially exposed to higher levels of trauma, which Jones and Nangah [3] cite to be another factor that can influence a student's psychosocial and academic trust levels. Ultimately, trust is considered as a two-way exchange between students and the HEI. According to Baier [21], 'Trust is a notoriously vulnerable good, easily wounded and not at all easily healed'. This highlights the precariousness of success or failure based on the concept of trust within a HE context, demonstrating the need for careful consideration in relation to the WP demographic, especially if social mobility is to succeed.

\subsection{Psychosocial and academic trust alienation theory}

It seems logical, therefore, to consider that these factors could be interconnected in the HE environment, particularly for WP students. Many of these students have had either a large gap from education, previously gained low attainment grades from school or experienced disadvantage and hardship $[4,15,22]$. These students possibly present gaps between the ideal 
self and the perceived self' [18], impacting on their ability to cope within their programmes of study from the outset. This can then manifest as discrepancies between self-concept and self-esteem affecting their HEI experience. According to Mann [2], Jones [1] and Jones and Nangah [3], discrepancies in self-concept and self-esteem can create barriers to student engagement though alienation.

Schaffer [18] asserts that self-concept can range from low to high, with the ability to move up or down in reaction to changing behaviours from other people. This is closely linked to the appraisal of the extent of the student's own failed experiences as a consequence of their own set standards. The suggestion of an interchangeable continuum leads to an assumption that there is scope for the student's psychosocial self-concept to be increased or decreased dependent on their own view of themselves, but also in response to assessment by others. This idea further relates with the psychosocial idea of self-concept in terms of trust [17].

Potentially, if trust is developed effectively with HE staff then this would improve student confidence and security in the HEI. However, if trust is not successfully achieved, this can lead to students feeling alienated based on their own individual psychosocial status. The 'psychosocial and academic trust alienation theory' connects the elements of students' psychosocial, academic trust and engagement, and thus proposes an original concept of alienation theory. (see Figure 1)

\section{Barriers to Student Engagement}

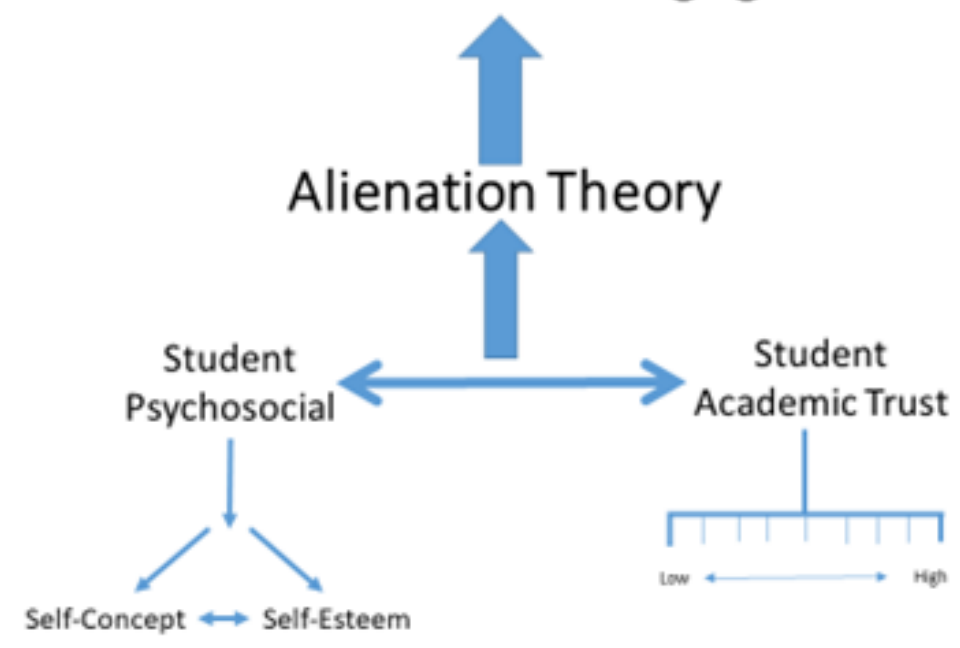

Figure 1 'The psychosocial and academic trust alienation theory'

Whilst, psychosocial status and trust could all be linked within the academic environment, there have been no studies undertaken to substantiate the links between these concepts. Knowledge of this view could enable HEI's to consider the power of the relationship between the internal world of the student and the social environment in which they are positioned as part of their programmes of study.

\section{Materials and methods}

\subsection{Participant institution context}

This study was undertaken at a HE campus based within an FE Institution in the United Kingdom. The HE campus delivered a range of social science foundation degree and topup degree programmes to the local areas via collaborative partnerships with several main universities. Historically university collaborative partnerships were established and based within local college campuses to encourage attendance of the WP demographic by offering diversity of HE provision, increasing accessibility and thus the ultimate goal of improving social mobility [23].

The local demographic consisted of mixed social economic groups, including significant representation from areas of relative deprivation, Black Minority Ethnic (BME), including those with English as an additional language and the local population. In the 2017/2018 academic year, the gender representation was $69 \%$ female and $31 \%$ male. This gender divide appeared to be directly linked to the significant enrolment on Health and Social Science courses, Teacher Education and Early Years, all of which consist of mainly female applicants. 
Ethnicity statistics for the institution highlight that $45 \%$ were BME students and $55 \%$ were from White British groups. In contrast, the national population of students in England in 2016 was $26 \%$ BME and $74 \%$ White British [25].

The institution also has a higher than average mature student population with $28 \%$ of students being under the age of 21 and $72 \%$ of students being over 21 . For comparison, the national average in England for students aged 21 and under is 56\%, and 44\% for over 21's [25]. This contextual data signifies the diverse nature of the participating HEI recognised as providing education for an entirely WP student market [15].

\subsection{Instruments}

A constructivist epistemology, underpinned by symbolic interaction theory utilising a mixed methods approach formed the research design [26-28]. Data was collected and analysed using quantitative and qualitative techniques, as appropriate to the mixed methods research design [29]. Quantitative and qualitative research customs and data collection methods provided opportunities to triangulate the data during the analysis process, providing differing viewpoints from both the student and teaching staff [30].

\subsubsection{Quantitative Likert scale questionnaire}

The main primary data was collected via a developed quantitative Likert scale questionnaire (Table 1 and 2) for students to determine their opinions of their own psychosocial (self-concept, self-esteem) in relation to their academic trust levels. The questionnaire was designed for online completion due to the personal and complex nature of the subject matter. Every effort was made to protect the participants; student, staff and institution from negative or harmful responses [32]. Therefore, the focus of the questionnaire was limited to four main sections:

(1) Demographic data

(2) Self-concept status

(3) Self-esteem status

(4) Academic trust

Questionnaire sections were designed around the following themes:

(1) HE experience

(2) Feedback

(3) Assessment results

(4) Communication with staff

(5) Communication with peers

(6) HE systems.

This provided opportunities for comparisons during the analysis process and also demonstrated objectivity to minimise bias [29]. A Bristol online [31] questionnaire was sent to all 557 students enrolled at the participating institution via email. Questionnaires were completed by 39 students, which equates to $7 \%$ of the student population and the questionnaire results were analysed using Excel to report the responses and average scores to address the research intention. This process enabled identification of anomalies, commonalities and points for further examination. This was used to organise and evidence a rigorous and robust approach to the analysis process and presentation of the results [33]. In terms of generalisability, the response rates would appear low, however, as a new concept being tested for the first time, the results needed to be manageable and have demonstrated significance. This data collected specifically contributes to research questions 1 and 2 .

\subsubsection{Qualitative case study}

An additional method of data collection was a qualitative student case study where respondents from the quantitative Likert scale questionnaire were offered the opportunity to participate [28]. The identification of outlier results drove the rationale for the case study, to scrutinise why anomalies were reported in more detail. The results were analysed using a thematic method, underpinned by the Likert scale questionnaire sections, contributing to a triangulated approach by utilising the diversity of mixed methods data collection [34]. The case study results provided additional insight in relation to research question 1 and 2 . There were two outlier participant responses identified, which required further examination. Both of these participants were invited to take part as a case study. One accepted (Participant 17), providing additional scrutiny contributing to further understanding of the 'psychosocial and academic trust alienation theory'. One declined, exercising their ethical right [32]. Extracts of the case 
study are presented in the results section to add additional insight by providing contextual data relating to their HEI experiences [29].

\subsubsection{Qualitative focus groups}

Additional data collection took place using qualitative semi-structured HE staff focus groups; four participants took part in two separate focus groups. These were designed to explore staff perceptions and experiences of students' barriers to engagement, based on the relationship between students' psychosocial status and levels of 'academic trust' [29,33]. Focus group discussions took place that aligned with the student online questionnaire themes. Results were analysed using a thematic approach, by examining the responses alongside the quantitative data collected and the case study narrative. Thematic analysis enabled the coding process through the identification of common terms, subjects and responses from the participants, which added further narrative to the quantitative data collected [29]. The thematic analysis process also contributed to triangulation of the research intention by gathering data from differing viewpoints into the complexities of the experiences of WP students during their HE experiences from the perspective of the teaching staff [33]. This data collection method specifically linked to research question 3.

\subsection{Ethics}

Ethical approval for the study was granted from the participating HEI and the participants prior to initiation of the research [32]. Participant ethics were met as per the Data Protection Act [35], GDPR [36] requirements and BERA [32]. Data responses were anonymised by numbering, to prevent identification of the participants [29].

Because of the complex and sensitive nature of the study, a data collection pilot was undertaken with a small sample of students, staff and HE education professionals [29]. This aided the risk assessment process and contributed to finalised terminology, appropriateness and interpretation of questions (33). This also tested the validity of the data obtained by the main data collection contributing to rigour, reliability and minimisation of bias [37]. This demonstrates the careful and measured approach taken as part of the research design process by evidencing deep consideration for the reduction of potential risk of harm to all participants; students, staff and institution [32].

Table 1 Research questions for likert scale quantitative data collection (self-concept and self-esteem)

\begin{tabular}{|c|c|c|c|}
\hline Questions & Self-Concept & Self-Esteem & $\begin{array}{c}\text { Likert Scale } \\
1 \text { (low) } 5 \text { (high) }\end{array}$ \\
\hline $\begin{array}{l}\text { 1. Understanding the teaching delivered during the course lessons? } \\
\text { 2. Accessing the course information outside the classroom (via Moodle or the library resources)? } \\
\text { 3. Participating in the following classroom learning activities: } \\
\text { a) group work } \\
\text { b) Role Play } \\
\text { c) Group Presentations } \\
\text { d) Individual Presentations } \\
\text { e) Quizzes } \\
\text { f) Matching tasks (e.g. key terms \& definitions) } \\
\text { g) Reading tasks (e.g. researching journals, case studies) } \\
\text { 4. Working independently outside of taught sessions? } \\
\text { 5. Understanding the assignment requirements of the course? } \\
\text { 6. Completing the following types of assessment: } \\
\text { a) Essays } \\
\text { b) Presentations } \\
\text { c) Case Studies } \\
\text { d) Reports } \\
\text { e) Exams } \\
\text { f) Portfolio } \\
\text { 7. Reading all assignment feedback? } \\
\text { 8. Using assignment feedback to improve your work for future submission? } \\
\text { 9. Developing working relationships with class peers during class activities? } \\
\text { 10. Forming relationships with class peers that continue outside of the University environment? } \\
\text { 11. Developing relationships with teaching staff? }\end{array}$ & & & \\
\hline
\end{tabular}


Table 2 Research questions for likert scale quantitative data collection (trust)

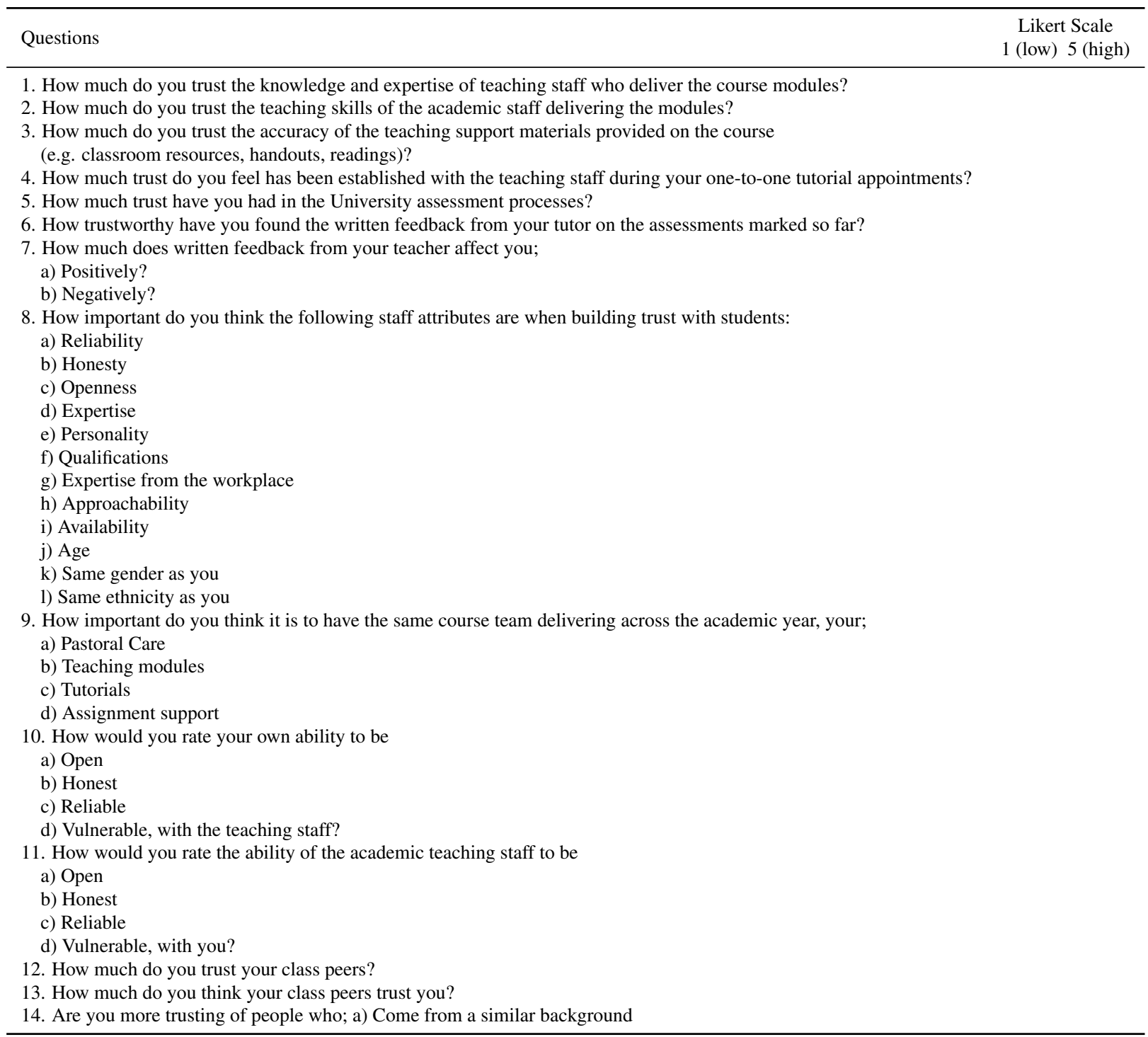

\section{Results}

\subsection{Results of self-concept and self-esteem analysis comparisons}

Links to research questions 1 and 2:

(1) What are students' perceptions and experiences of barriers to engagement resulting from their own psychosocial self-concept and levels of 'academic trust'?

(2) How do these influence barriers to student engagement through alienation?

The participant results for Questions 1-11 reported little difference between self-concept and self-esteem, with most responses at the higher end of the Likert scale (4's and 5's - Figure 2) These evidenced $87 \%$ of high levels of self-concept together with high levels of self-esteem meaning that there are only minor discrepancies between the students ideal and perceived real self [18], reported. This formed the first stage of the psychosocial theory investigation; examining whether discrepancies in self-concept and self-esteem lead to barriers to engagement.

\subsection{Results of self-Concept, self-Esteem and academic trust aver- age scores comparison and analysis}

Links to research questions 1 and 2:

(1) What are students' perceptions and experiences of barriers to engagement resulting from their own psychosocial self-concept and levels of 'academic trust'? 


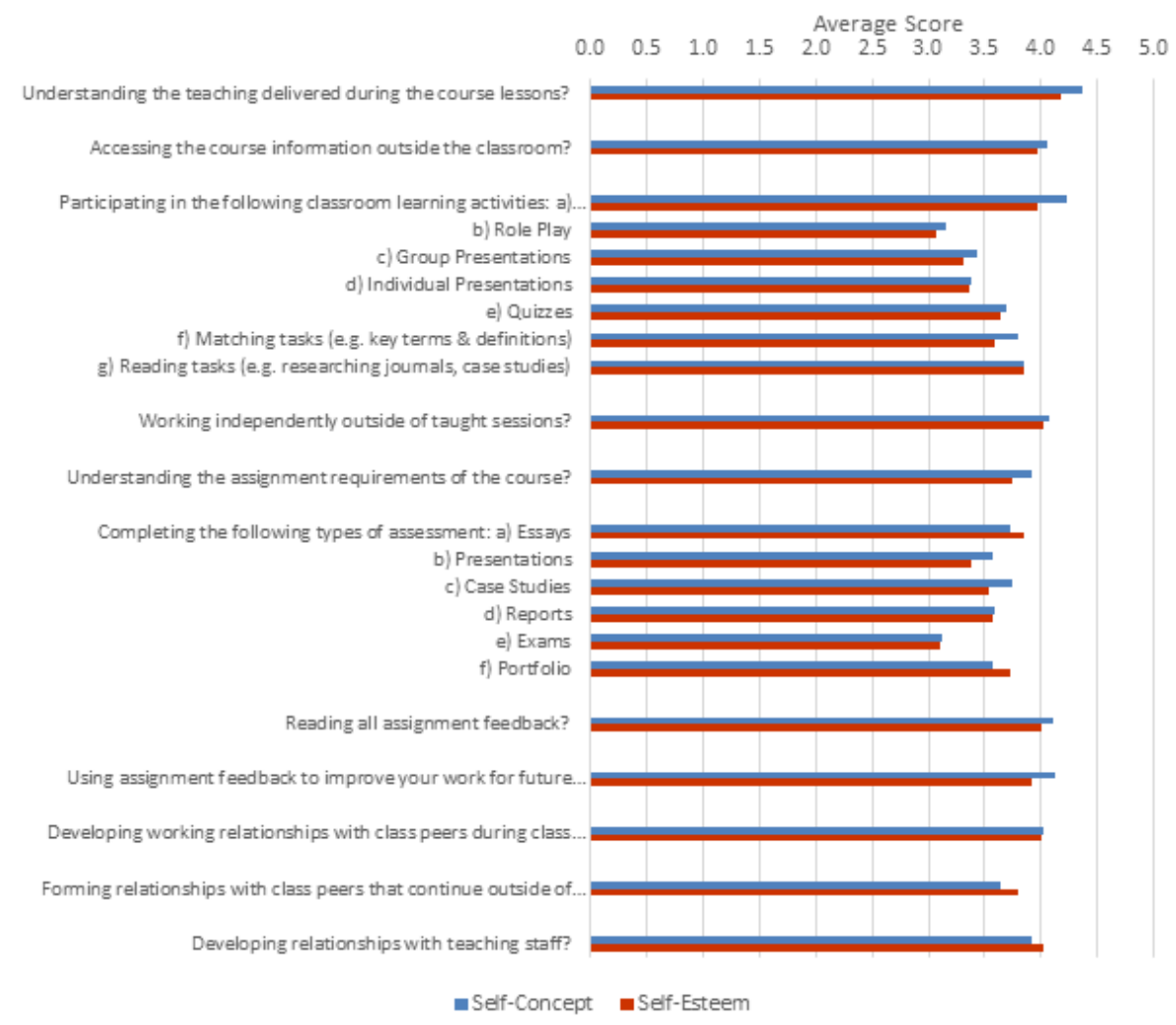

Figure 2 Average self-Esteem and self-confidence scores for Q1-11

(2) How do these influence barriers to student engagement through alienation?

Average scores for the domains of self-concept, self-esteem and academic trust were generated using excel formulas then examined further to identify if responses evidenced the psychosocial and academic trust alienation theory [1]. Analysis of these average scores revealed that $n=29(74 \%)$ of participants (Figure 3$)$ presented with similarities in their self-concept and self-esteem Likert scores evidencing high levels of trust within their academic experiences. Therefore, these participants can be determined as aligning with the concept of the psychosocial and academic trust alienation theory [1].

The remaining $n=10(26 \%)$ participant responses showed potential anomalies that did not identify as aligning with the alienation theory of the psychosocial and academic trust [1] (Figure 4). Therefore, these responses were further scrutinised to identify reasons why, and to categorise what the potential barriers to student engagement could be and these results were scrutinised more explicitly to identify reasons for these outliers, detailed below.

\subsection{Results of further scrutiny of $\mathbf{1 0}$ participant outliers}

Following further scrutiny of the raw data, it was discovered that the responses for the $n=10$ identified participants outliers could be organised into specific groups.

\subsubsection{Higher self-concept than self-esteem $=$ Low academic trust}

Participants 6 and 17 reported with higher self-concept than self-esteem scores and exhibited low academic trust. The barriers to engagement reasons for these students displaying low academic trust were identified as relating to:

(1) Participating in; individual presentations, group presentations, role play and independent work.

(2) Completing assessments of; presentations, essays, exams and portfolios.

(3) Understanding the teaching and learning delivered.

(4) Accessing the course content outside of the classroom (Moodle, Library).

(5) Relationships with staff.

Participant 17 provided contextual detail within the case study to enlighten more explicitly the barriers. These included a lack of confidence with many assessment and classroom tasks, 


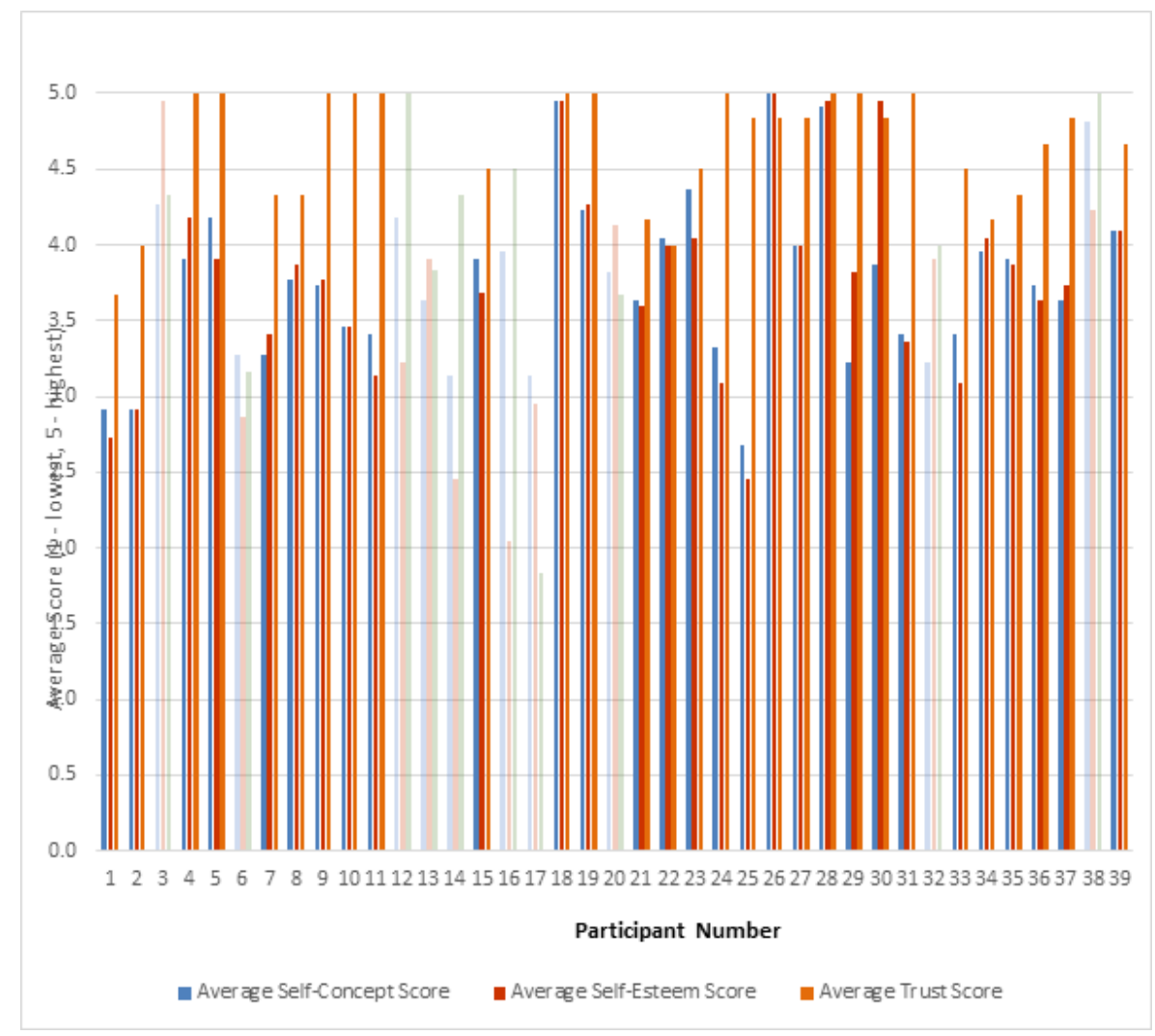

Figure 3 Average self-concept, self-esteem \& trust scores for each participant: High self concept, high self-esteem, high trust

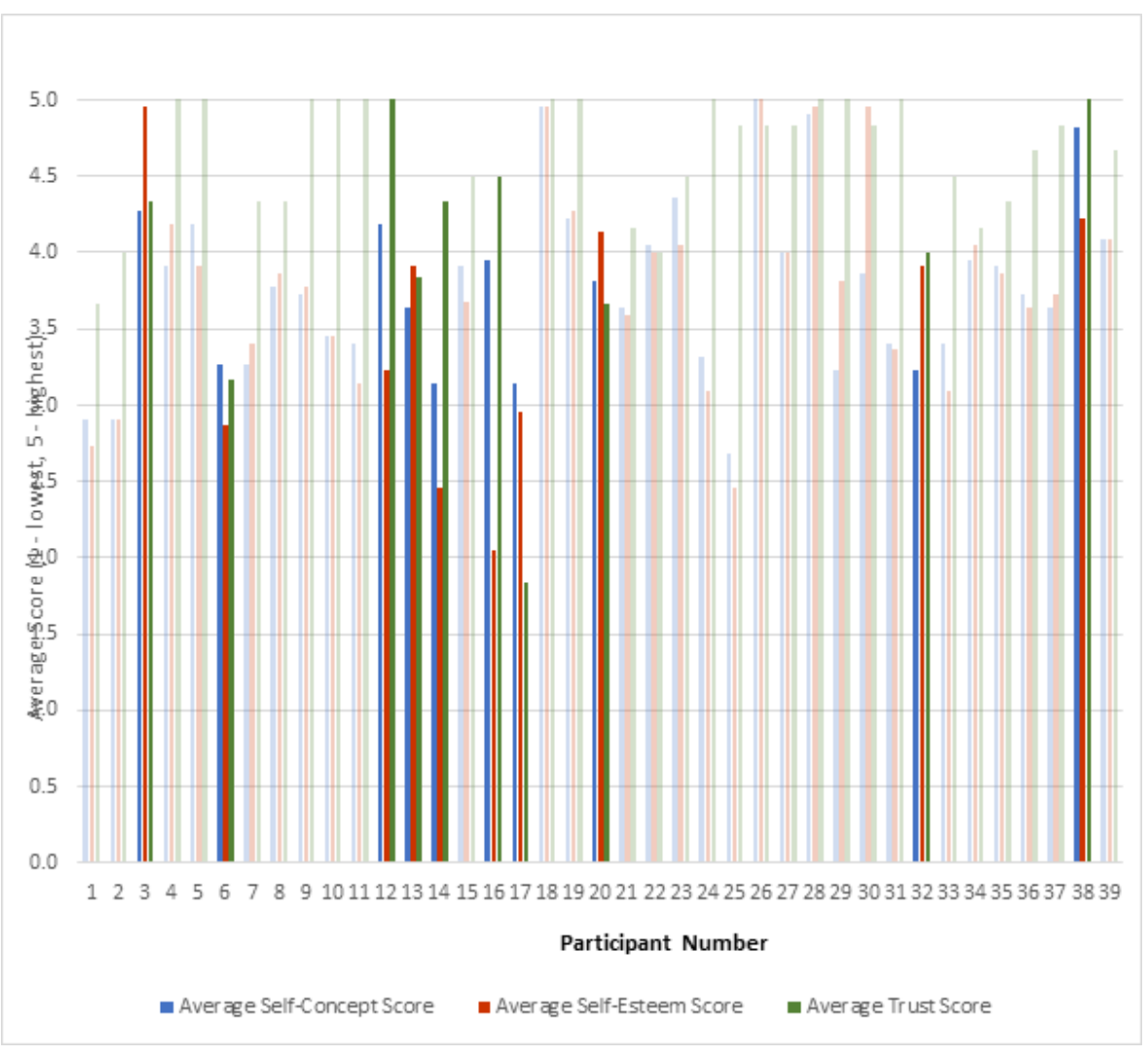

Figure 4 Average self-concept, self-esteem \& trust scores for each participant: Outliers 
particularly those that required presentations or speaking in front of a large group. They also mentioned difficulties with relationships with staff specifically related to high staff turnover that were affecting their abilities to cope.

Participant 6 did not give permission to be contacted to take part in the case study.

Jones [1] states '... students whose self-concept is based on lower self-esteem appear more mistrustful of the HE experience and, therefore, suffer feelings of alienation which lead to barriers to engagement' evidencing that these participants responses align with the psychosocial and academic trust theory [1].

\subsubsection{Higher self-concept than self-esteem $=$ High academic trust}

Participant 12,14, 16 and 38 reported with self-concept scores higher than self-esteem leading to high levels of academic trust. On closer inspection this could mean that these students seem to be doing better than they think they are; they are more capable than confident, leading to high academic trust. Whilst these results do not align with the psychosocial and academic trust alienation theory [1], a rational explanation of this anomaly has been identified here.

\subsubsection{Higher self-esteem than self-concept $=$ Low academic trust}

Participant 3's responses identified self-esteem higher than self-concept (evidencing a gap between '... perceived real self and ideal self...', [18]) and presented with lower academic trust. The individual scores for this student were scrutinised to determine what was driving the potential barriers to engagement. The student reported low Likert scores when answering the questions, which related to staff and peer relationships, together with reading tasks and accessing the course content outside of the classroom (Moodle, Library). This indicates that this student's self-concept is affected by these elements, perhaps leading to low academic trust and creating barriers to engagement, thus aligning with the psychosocial and academic trust alienation theory [1].

\subsubsection{Higher self-esteem than self-concept $=$ High academic trust}

Participant 32 reported higher self-esteem than self-concept and high academic trust. These results for self-concept being lower could be attributed to: Participating in group work, role play, presentations, quizzes and key terms matching tasks, reading tasks and exams.

For this participant, it may be the case, that their high self-esteem (confidence) has clearly impacted on their trust levels. It could be that their self-esteem has provided them with the security to be able to trust in the academic system assuming that the academic processes will provide the 'capability' support they will need. However, although this student has presented with high trust, there are still barriers to engagement, which have been identified. This participant, arguably, does not align to the psychosocial and academic trust alienation theory [1].

\subsection{Qualitative data collection for staff focus groups}

Links to research question 3: What are HE staff perceptions and experiences of students' barriers to engagement, based on the relationship between students' psychosocial self-concept and levels of 'academic trust'?

The findings from the focus groups provided additional context to some of the student questionnaire scores obtained from questions 1-11 (Table 1 and 2) via the opinions of HE teaching staff. The qualitative data collected provided valuable insights and contextual understanding from more than one standpoint contributing to the justification of a mixed methods approach $[26,29,33]$. Drawing on both quantitative and qualitative data results enabled the research to offer richness, varied viewpoints and through the thematic analysis of this qualitative data has contributed further to triangulation of the research intention [27] as follows:

Results of Question 2 concerning accessing the course information outside the classroom (via Moodle or the library resources) had some lower responses reported (2's and 3's Likert scale). This indicates that there are some participants who are less confident using these resources. Focus group 2 reported that mature students often present with barriers to accessing Moodle and online resources and the use of computers. The staff talked at length about the significant barrier this is creating for mature students. They also acknowledged that despite help from staff, these students continued to alienate themselves by not trusting the technology. Staff reported that these students are very capable academic writers, however, the barriers to the technology impacts trust levels. This evidences an example of barriers to engagement based on the psychosocial and academic trust alienation theory [1]. The participating institution has a 
$72 \%$ student population who are over the age of 21 signifying that a large proportion of students are categorised as 'mature' and meaning that technology barriers could be further widespread than current HE practice considers. P17 concurred, citing barriers to engagement arising from a lack of IT knowledge.

Question 3 (Figure 1) reports students' self-concept and self-esteem relating to participating in classroom activities. Results show the strongest responses in 'group work' activities and the lower or more variable responses relating to 'role play, group and individual presentations'. This suggests that for these students these tasks could present a barrier to student engagement with the potential to lead to alienation $[1,2]$. The focus groups highlighted presentations as assessment points, which most affect students' self-concept and self-esteem, with one participant stating "... they hate it, they hate it and their confidence just dips". This statement concurs with the results reported in response to Question 3 (Figure 3). Group work evidences Hawley's [11] ideas of trust being a three way exchange between two sets of individuals (teacher/students) and a set task. Students could learn to develop trusting relationships through active learning teaching techniques such as group work. Yorke and Longden [38] highlight Tinto's (1993) theory of social and academic engagement as being critical to students' success. These responses to Question 3 suggest that the respondents prefer to be engaged in group work active learning opportunities, which aligns with the social and academic ideas of Tinto (1993) [38]. Participant 17 explained that complications in class peer and staff relationships affected her self-concept and self-esteem evidenced by lower Likert scale scores. This was attributed to interruptions to relationships caused by staff sickness and disagreements with fellow peers.

Similar responses are reported for Questions 7 and 8 (Table 1 and Figure 1) for reading assignment feedback and using assignment feedback to improve work, with generally high scores recorded for both. Tarquin and Cook-Cottone [6] state that when students are dissatisfied with their feedback this can interfere with their confidence (self-esteem) levels. Davis and Dargusch [12] add that the quality of feedback provided can have a profound impact on students' ability to trust. According to the Focus groups, those students who need most help with reading and interpreting feedback are the least engaged and least trusting students, adding "it's those that are harder to reach" or those students who alienate themselves and almost consciously "self-sabotage" [7,39]. Furthermore, it was reported that "some of them [students] won't put drafts in because they are afraid of what they are going to get as feedback for that [work]". This highlights some potential barriers to engagement directly linked to reading and interpreting feedback [40]. However, this was not evidenced by the responses to the survey. It is important to note that the questionnaire results reflect $5 \%$ of the HEI's population who report as engaging successfully, which may be a different student population to that described above. The focus groups also stated that some students '... just want to lap it all up, they want to do the best they can, they ask questions all night long and all day long and they get responses and work with it' . This statement aligns more closely with the respondents of the survey. Participant 17 stated "this [feedback] was her biggest bug bare" and she reported a lack of trust in relation to the feedback provided by new staff/covering staff, which caused arguments, anguish and strained relationships with staff.

Figure 1, also further highlights the relatively low scores associated with participation in role play, group and individual presentations and examination assessments as discussed above.

\section{Discussion and conclusion}

This research investigated students' perceptions and experiences of barriers to engagement in an HE in FE institution [15,41]. Furthermore, it also explored HE staff perceptions and experiences of students' barriers to engagement, based on the relationship between 'psychosocial and academic trust alienation theory' [1].

The results revealed that $87 \%$ of the total participant student sample aligned with the concept of the 'psychosocial and academic trust alienation theory' [1]; 74\% of the sample reported high levels of self-concept and significantly higher levels of academic trust and no influencing barriers to engagement. However, $13 \%$ of the participant sample evidenced discrepancies between self-concept (higher) and self-esteem (lower), and reported low levels of academic trust. The influencing barriers attributed to student alienation based on the "psychosocial and academic trust theory' were:

(1) Participating in: individual presentations, group presentations, role play, independent work, and reading tasks.

(2) Understanding the teaching and learning delivered.

(3) Completing assessments (exams, presentations, essays and portfolios).

(4) Accessing the course content outside of the classroom (Moodle, Library). 
(5) Student/lecturer relationships affected by high turnover of staff.

(6) Relationships with class peers.

The remaining $13 \%$ of the participant student sample did not directly align with the 'psychosocial and academic trust theory' [1]. Although, on further scrutiny similar influencing barriers to student engagement were identified in this group.

Strategies used by the focus group staff appear to be extremely effective for supporting WP students, as reported in their responses. These included; regular academic and personal tutorials, face to face (and one-to-one) feedback sessions even at the cost of lecture time. The staff evidenced bespoke positive psychological counselling, coaching and mentoring strategies to support students, although all focus group staff highlighted difficulties engaging with 'hard to reach' students who alienate themselves and display mistrusting behaviours. Staff absences and turnover also had a significant impact on students' psychosocial and academic trust, caused by these interruptions to relationships. Therefore, these results confirm the interconnection between the students' psychosocial self-concept and academic trust as barriers to engagement in HE. This validates 'the psychosocial and academic trust theory' in HE practice as a new and original contribution to alienation theory [1-3].

These results illustrate that, for the participating HEI, barriers to student engagement could be reduced and success rates increased, if attention was directed to develop practice based on 'the psychosocial and academic trust alienation theory' [1]. This could be achieved by:

(1) Bespoke intervention or 'black box' packages for students identified with barriers to engagement, or who are displaying alienating behaviours aligned to the 'psychosocial and academic trust theory' $[1,3,42]$. Counselling, coaching and mentoring approaches could be embedded as these are effective strategies for WP students. This may increase retention, quality, student engagement and success rates $[25,43,44]$. This suggests a move towards a social pedagogical HE culture is needed. With HE funding tied to student satisfaction this may well be a sensible time to develop HE practice to meet the contextual needs of the HEI and the WP demographic $[42,45]$.

(2) Make every effort to maintain a consistent staff team of lecturers, course leaders and support staff, with whom students can build trust and develop tacit knowledge throughout their academic journey. Aim to reduce staff turnover to protect students from disruptions in their HE experience resulting directly from the consequences of staff sickness, associate lecturer or hourly paid posts, fixed term posts and resignations. This would provide students with consistency of care and education throughout their university journey.

(3) Include protected tutorial/pastoral modules in staff timetables/workloading, to provide time and space to focus on building trusting relationship with students. Regular personal tutorials and face-to-face assessment feedback opportunities should be implemented to cultivate trusting relationships as part of programmes of study.

(4) Embed social pedagogical and psychological educational practices into teacher training, to strengthen the skills of the HE workforce.

(5) Embed additional peer based active learning strategies, such as group work or team building opportunities, into the HEI culture to facilitate trusting environments and a community culture.

This research reinforces that it is vital within the current HE landscape to adapt practice to meet the needs of the diverse student population [4, 42, 46, 47]. This means evolving practice and thinking creatively to enable disadvantaged students the opportunity to thrive and succeed in their chosen area of study [41,43]. Although there is considerable pressure on the HEI's to meet government targets for recruitment, retention and achievement, it is morally right to adapt practice so that it is fit for purpose, and offers inclusivity and equality of opportunity $[4,25,44-46]$. By adapting practice, this has the potential to increase the quality of teaching and learning for the students, which in turn may impact on recruitment and retention of both staff and students, leading to overall success and satisfaction rates. If the true spirit of the WP agenda is to be fulfilled, then it is crucial that HEI's contextualise the needs of their market. The 'psychosocial and academic trust alienation theory' [1] could be a useful tool to support HEI and student outcomes underpinned by a social pedagogical approach to the HE experience for WP students and wider.

Therefore, the contribution of this research to the field of HE and educational psychology is three-fold; firstly, this supports the presence of the 'psychosocial and academic trust alienation theory', secondly it provides insights into the psychological barriers to engagement for the WP student demographic, thirdly it proposes practical strategies for supporting WP student success.

There is an argument for further research to be undertaken across a wider HEI sample group, perhaps using alternative data collection methods, with an analysis of attendance, dropout and succession rates of WP students, to further strengthen and validate this theoretical perspective. However, the results and key findings provide original insights that can be shared 
across HEI's with similar demographics and WP student populations. Thus, revealing potential generalisability of the findings and recommendations for the United Kingdom and international HE sector. Studies of new theoretical perspectives can bring additional knowledge to those who provide education who strive to improve outcomes for those most disadvantaged. It is without question, in the best interests of the student and the HEI to foster and invest in trusting relationships and systems, to reduce barriers to student engagement and increase student success by pro-actively committing to the social mobility agenda.

\section{Conflict of interest and funding}

No potential conflict of interest was reported by the author. No Funding was obtained for this research article.

\section{References}

[1] Jones CS. Barriers to Student Engagement in HE: Revisiting Concepts of Alienation, 2017. http://www.celt.mmu.ac.uk/ltia/Vol12Iss2/2_Jones_barriers_to_student_engagement_in_HE revisiting_concepts_of_alienation.pdf

[2] Mann SJ. Alternative Perspectives on the Student Experience: Alienation and Engagement. Studies in Higher Education, 2001, 26(1): 7-19. https://doi.org/10.1080/03075070020030689

[3] Jones CS and Nangah Z. Higher education students: barriers to engagement; psychological alienation theory, trauma and trust: a systematic review. Perspectives: Policy and Practice in Higher Education, 2020, 25(2): 1-10. https://doi.org/10.1080/13603108.2020.1792572

[4] Augar P. Chair, Post-18 Education and Funding Review Panel: Independent panel report to the Review of Post-18 Education and Funding. Crown Copy Right, 2019. https://assets.publishing.service.gov.uk/government/uploads/system/uploads/attachment_data/file/ 805127/Review_of_post_18_education_and_funding.pdf

[5] Bronfenbrenner U. Preventing Alienation: Alienation and the Four Worlds of Childhood. The Phi Delta Kappan International, 1986, 67(6): 430-436.

[6] Tarquin K and Cook-Cottone C. Relationships Among Aspects of Student Alienation and SelfConcept. School Psychology Quarterly, 2008, 23(1): 16-25. https://doi.org/10.1037/1045-3830.23.1.16

[7] Çalar C. Development of the student alienation scale (SAS).Egitim ve Bilim-Education and Science 2012, 37(166): 195-205.

[8] Çalar C. The Relationship between the Levels of Alienation of the Education Faculty Students and Their Attitudes towards the Teaching profession. Education and Science, 2013, 13(3: 1507-1513.

[9] Barnhardt B and Ginns P. An alienation-based framework for student experience in higher education: new interpretations of past observations in student learning theory. High Education, 2014, 68: 789805 . https://doi.org/10.1007/s10734-014-9744-y

[10] Gibbs P. Competence or Trust: The academic offering. Quality in Higher Education, 1998, 4:1: 7-15. https://doi.org/10.1080/1353832980040102

[11] Hawley K. Trust, Distrust and Commitment. NOUS, 2014, 48(1): 1-20. https://doi.org/10.1111/nous.12000

[12] Davis SE and Dargusch JM. Feedback, Iterative Processing and Academic Trust - Teacher Educations Students' Perceptions of Assessment Feedback. Australian Journal of Teacher Education, 2015, 40(1) 177-191.

https://doi.org/10.14221/ajte.2015v40n1.10

[13] Ennen NL, Stark E and Lassiter A. The importance of trust for satisfaction, motivation, and academic performance in student learning groups. Social Psychology of Education, 2015, 18: 615-633. https://doi.org/10.1007/s11218-015-9306-x

[14] Hoon CH and Geertsema J. Fostering community, building trust, and navigating risks in academic development. International Journal for Academic Development, 2016, 21(3): 163-165. https://doi.org/10.1080/1360144X.2016.1203572

[15] Vignoles A and Murray N. Widening participation in higher education. Education Sciences. Education Science, 2016, 6: 13 . https://doi.org/10.3390/educsci6020013

[16] Case J. Alienation and engagement: development of an alternative theoretical framework for understanding student learning. High Education, 2008, 55: 321-332. https://doi.org/10.1007/s10734-007-9057-5

[17] Walker J and Crawford K. Social Work and Human Development. Exeter: Learning Matters Limited, 2010.

[18] Schaffer RH. Social Development. Oxford: Blackwell Publishers, 2000. 
[19] Heffernan T, Wilkins S and Butt M. Transnational higher education The importance of institutional reputation, trust and student-university identification in international partnerships. International Journal of Educational Management, 2017, 32(2): 227-240. https://doi.org/10.1108/IJEM-05-2017-0122

[20] Kharouf H, Sekhon H and Roy SK. The components of trustworthiness for higher education: a transnational perspective. Studies in Higher Education, 2015, 40(7): 1239-1255. https://doi.org/10.1080/03075079.2014.881352

[21] Mcmurrin SM. The Tanner Lectures on Human Values. Ethics, 2011, 20(2): 175-177. https://doi.org/10.5840/idstudies 199020213

[22] Connell-Smith A and Hubble S. Widening Participation Strategy in Higher Education in England. House of Commons Library: Briefing Paper 8204, 2018. http://researchbriefings.files.parliament.uk/documents/CBP-8204/CBP-8204.pdf

[23] Department for Business, Innovation and Skills. Higher Education: Students at the Heart of the System, 2011.

https://assets.publishing.service.gov.uk/government/uploads/system/uploads/attachment_data/file/ 31384/11-944-higher-education-students-at-heart-of-system.pdf

[24] Department for Communities and Local Government. (2015) National Statistics: The English Indices of Deprivation 2015.

https://assets.publishing.service.gov.uk/government/uploads/system/uploads/attachment_data/file/ 465791/English_Indices_of_Deprivation_2015_-_Statistical_Release.pdf

[25] HEFCE. (2016) Equality and Diversity Data 2016. http://www.hefce.ac.uk/data/year/2015/eddata

[26] Crotty M. The Foundations of Social Research. London: Sage Publications, 2012.

[27] Denscombe, M. (2011) The Good Research Guide (4th Edition). Berkshire: Open University Press.

[28] Mackenzie N and Knipe S. Research Dilemmas: Paradigms, methods and methodology. Issues in Educational Research, 2006, 16(2): 193-205. http://www.iier.org.au/iier16/mackenzie.html

[29] Cohen L, Manion L and Morrison K. Research Methods in Education, 7th Edition, Oxon: Routledge Falmer, 2011.

[30] JISC. (2020) Online Surveys formerly BOS. https://www.onlinesurveys.ac.uk

[31] Opie C. Doing Educational Research. London: Sage Publications, 2004.

[32] BERA. The British Educational Research Association, 2017. https://www.bera.ac.uk

[33] Bryman A. Social Research Methods (4th Edition). Oxford: Oxford University Press, 2012.

[34] Golafshani N. Understanding reliability and validity in qualitative research. The Qualitative Report, 2003, 8(4): 597-606. http:/www.nova.edu/ssss/QR/QR804/golafshani.pdf

[35] Data Protection Act 1998. https://www.legislation.gov.uk/ukpga/1998/29/pdfs/ukpga_19980029_en.pdf

[36] Data Protection Act 2018). https://www.legislation.gov.uk/ukpga/2018/12/contents/enacted

[37] Abdulai R and Owusu-Ansah A. Essential Ingredients of a Good Research Proposal for Undergraduate and Postgraduate Students in the Social Sciences. SAGE Open, 2014, 4(3): 1-15. https://doi.org/10.1177/2158244014548178

[38] Yorke M and Longden B. Retention and Student Success in HE. Berkshire: Open University Press, 2004.

[39] Neville L. Do Economic Equality and Generalized Trust Inhibit Academic Dishonesty? Evidence from State-Level Search Engine Queries, 2012, 23(4): 339-345. https://doi.org/10.1177/0956797611435980

[40] Carless D. Differing Perceptions in the feedback process. Studies in High Education, 2006, 31(2): 219-233. https://doi.org/10.1080/03075070600572132

[41] Crozier G, Reay D and Clayton J. The socio-cultural and learning experiences of working class students in higher education. University of Sunderland, 2008.

[42] Younger K, Gascoine L, Menzies V, et al. A Systematic Review of evidence on the effectiveness of interventions and strategies for widening participation in higher education. Journal of Further and Higher Education, 2019, 43(6): 742-773. https://doi.org/10.1080/0309877X.2017.1404558

[43] Crosling G, Thomas L and Heagney M. Improving Student Retention in Higher Education. Oxon: Routledge, 2007. https://doi.org/10.4324/9780203935453

[44] QAA. UK Quality Code for Higher Education: Assuring and Enhancing Academic Quality, 2016. http://www.qaa.ac.uk/assuring-standards-and-quality/the-quality-code/quality-code-part-b

[45] HEFCE. National Student Survey, 2018. http://www.hefce.ac.uk/lt/nss/results

[46] Grace S and Gravestock P. Inclusion and Diversity: Meeting the Needs of All Students. Oxon: Routledge, 2009. https://doi.org/10.4324/9780203890387

[47] QAA. Student Engagement, 2018. https://www.qaa.ac.uk/quality-code/advice-and-guidance/student-engagement 